\title{
Research on the Difficulties and Advantages of Experiential Japanese Teaching at FPT University, Ho Chi Minh City
}

\author{
${ }^{1 *}$ Nguyen Tan DANH
}

${ }^{1}$ Department of IT, FPT University, Vietnam, Email: danhnt16@fe.edu.vn

* Corresponding Author

\author{
Received: 12.08.2021 Accepted: 10.10.2021 Published: 04.12.2021 $\quad$ DOI: 10.47750/QAS/22.185.12
}

\begin{abstract}
One of the most important recent trends in higher education has been the move towards expanding the scope of the classroom, which often referred to as experiential education. This method is both a bridge between classroom learning and social life, transforms theoretical knowledge into practical knowledge. It is based on theories of experiential learning, a process by which learners interact with the world and integrate new learning into old methods. Experiential learning can lead to more effective learning, help students transition from university to work, and increase students' use of knowledge and critical thinking. The study was conducted to show the difficulties and advantages of this experiential teaching method. The article was completed based on the results of interviews and surveys from 20 students studying Japanese at FPT University in Ho Chi Minh City. The research results show that the majority of students have a basic awareness of experiential teaching and organize many useful activities, creating opportunities for students to develop professional competencies based on theory. However, there is still no connection between lecturers and students in activities and basic measures are needed to make the training program more complete.
\end{abstract}

Keywords: advantages, experiential education, difficulties, interaction, trends

\section{Introduction}

In the early years of the twentieth century, experiential teaching was developed and applied in many countries, including higher education and vocational training (Phuc, 2018). In fact, this teaching method has recently seen changes in the field of higher education. The driving force behind this change has been recognition from universities that the purpose of 21 stcentury education has evolved to include empowering students for self-directed learning, public rights, and self-directed learning, civil rights, and ecological sustainability in addition to traditional knowledge, skills, and attitudes in specific industries (Rickinson, 2001). All majors in general and the Japanese Language major of FPT University, in particular, need to prepare students with experiential programs so that they can apply their acquired knowledge to real-world problems. The driving factors add to the economic need for higher education institutions to interact more closely with Japanese businesses, the growing number of Japanese language learners but the declining job market and competition on professional skills besides basic skills such as listening, speaking, reading, and writing of Japanese gradually increased among graduates. The inclusion of experiential education in Japanese language curriculums was organized to increase student recruitment rates. To be able to achieve that goal, it is extremely necessary to learn more about the difficulties and advantages of experiential Japanese teaching at FPT University in Ho Chi Minh City.

\section{Research content}

\subsection{Literature review}

Some traditional teaching methods have been widely applied in all disciplines so far, such as problem presentation method, conversation method, etc. These methods each have their own advantages and disadvantages, but in general, the pedagogical approach places the main emphasis on the teacher as a transmitter of knowledge. However, when the concept of education not by listening but by experiencing the environment is given, that is when experiential education methods appear (Boggs et al., 2007). According to Bradley (2014), based on choice theory, the average person only learns 10\% from reading, $20 \%$ from hearing from others, while most knowledge can be absorbed is through actual experience. Therefore, instead of applying memorization of complex grammar rules and isolated words, experiential education will help students express language in context and develop skills necessary for future careers (Boumová, 2008). This method has also been shown to help people develop comprehensive skills such as observation skills, reasoning skills, behavioral skills, and critical thinking (Eyler, 2002). In addition, previous studies have shown that students are more likely to go on to graduate school at a significantly increased rate after participating in experiential learning as part of an undergraduate program. According to Piercy et al. (2012), although experiential teaching brings so many benefits to students, at the present time the application of this method is relatively limited in many aspects and there is still no best way to solve these problems. 


\section{GENERAL MANAGEMENT}

\subsection{The current situation of experiential Japanese teaching at FPT University in Ho Chi Minh City}

Being aware of the importance of experiential education methods, the Japanese language lecturers of FPT University have planned to organize activities in the form of extra-curricular activities, field trips to guide students in the future. Professional skills along with cooperation from institutions outside the school such as travel agencies, museums, exhibitions. In general, the programs initially aroused curiosity and excitement for students. Besides basic skills such as listening, speaking, reading, and writing, according to Piercy et al (2012), other skills such as interaction, communication, information gathering, conflict resolution, and coping with unexpected situations, etc. can also be facilitated to develop thanks to this teaching method. In addition, activities such as pretending to simulate situations in Japanese enterprises have also been applied in economic subjects to share with students about relationships with customers, partners, and management. company employees, etc. (Boggs et al., 2007). Thereby, the lecturers will combine the form of activities and the assessment method to be able to comprehensively assess the students' capacity (Phuc, 2018). However, this experiential model of Japanese language teaching currently has many limitations, such as many formal programs and plans have not been built in a specific way. There are several shortcomings that affect the effectiveness of instruction, including the cost and facilities required for outdoor activities.

\subsection{Methods, subjects and scope of research}

\subsubsection{Subjects and scope of research}

The object of the research is experiential education, mainly focusing on teaching Japanese using this method. The scope of the study is FPT University Ho Chi Minh City but mainly focuses on the Japanese language major.

\subsubsection{Methods}

Theoretical research results are based on analysis, synthesis, and selection from previous studies by reputable authors and organizations at home and abroad to clarify the research problem. Besides, in order to have more basis for scientific analysis on awareness and actual situation of organizing experiential education activities, at the quantitative research stage, the survey method by questionnaire was used because This is one of the most popular and widely used research methods for data collection (Piercy et al., 2012). The subjects of the survey were 40 students majoring in Japanese at FPT University in Ho Chi Minh City. The questionnaire consists of 11 questions, which mention the level of agreement or disagreement of the respondents and are evaluated basing on a 5-point Likert scale. The content of the survey aims to clarify the level of interest and awareness of students about experiential education, in addition, how to apply this teaching method in the training process, the advantages and disadvantages that have been identified. encountered in the implementation process and suggestions for trainers to organize experiential activities more effectively.

\subsection{Results and discussion}

The orientation of educational innovation associated with experience initially attracted the attention of students of FPT University. However, the level is not uniform and there are differences in perception. Most students believe that experiential education can play an important role in today's educational practice. It has been proven that $100 \%$ of students consider this teaching method necessary and essential in the training program in the higher education environment. However, only $4 / 20(20 \%)$ students have learned about this content while $16 / 20(80 \%)$ have chosen the answer that they have heard but have not learned (Figure 1).

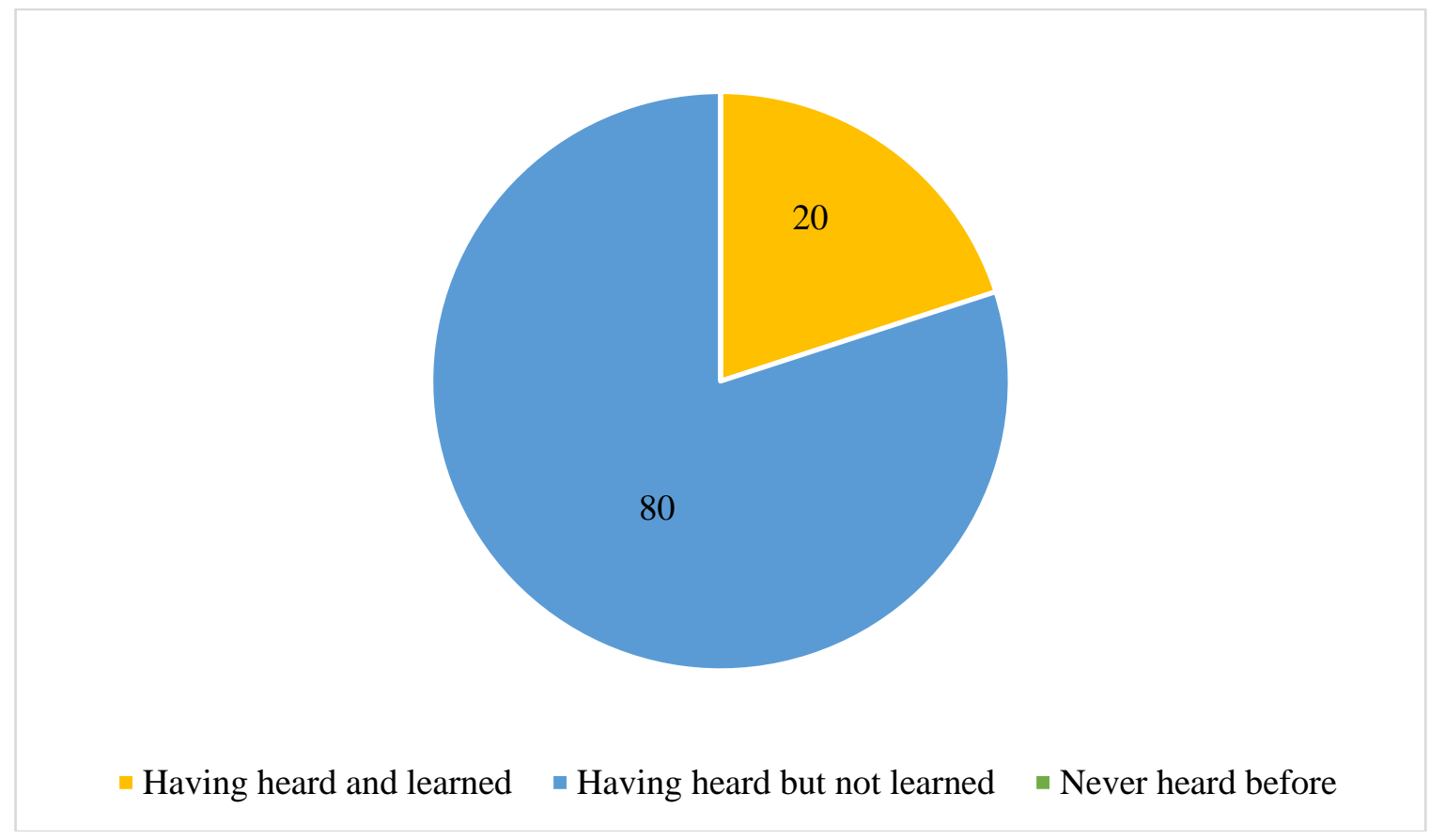

Figure 1: Students' access to experiential education

Besides, by using the 5-point Likert scale to evaluate from never to very often, students were asked to determine the frequency of using experiential teaching methods in lessons.
This study mainly focuses on four main methods: field visits, role-playing simulations, interactive games, and debates (Boggs et al., 2007). Thereby, the results show that teaching 


\section{GENERAL MANAGEMENT}

through field trips is rarely (45\%) and sometimes (25\%) organized. Debating is a method used very often $(30 \%)$ and often $(35 \%)$, of which only $10 \%$ of students think that this method is rarely organized. Simulation, role-playing seems to be another method of experimentation that is widely applied in lessons because it is held often (45\%) and occasionally (35\%). Finally, the method of teaching through interactive games is held regularly and very often with the ratio of $20 \%, 25 \%$ respectively, of which $15 \%$ of the respondents think that this method is rarely organized in the classroom (Table 1 ).

\begin{tabular}{|c|l|c|c|c|c|c|c|c|c|}
\hline No & \multicolumn{1}{|c|}{ Methods } & $\mathbf{1}$ & $\mathbf{2}$ & $\mathbf{3}$ & $\mathbf{4}$ & $\mathbf{5}$ & $\begin{array}{c}\text { Total } \\
\text { answers }\end{array}$ & $\begin{array}{c}\text { Total } \\
\text { score }\end{array}$ & $\begin{array}{c}\text { Average } \\
\text { frequency }\end{array}$ \\
\hline 1 & Field trip & 1 & 9 & 5 & 2 & 3 & 20 & 57 & 0.21 \\
\hline 2 & Simulation, role-play & 1 & 2 & 7 & 9 & 1 & 20 & 67 & 0.25 \\
\hline 3 & Interactive game & 0 & 3 & 8 & 4 & 5 & 20 & 71 & 0.26 \\
\hline 4 & Debate & 0 & 2 & 5 & 7 & 6 & 20 & 77 & 0.28 \\
\hline
\end{tabular}

Table 1: Frequency of using experiential education methods

Furthermore, also using a 5-point scale from strongly disagree to strongly agree, students taking the survey were asked to express their views with four statements related to experiential education methods (平田千春 et al., 2008). The results show that the majority of students completely agree $(25 \%)$ and agree $(40 \%)$ that the experiential teaching method will help the connection between lecturers and students become closer while $7 / 20$ (35\%) people expressed neutral or disagreed views. Next, the study focused on students' opinions regarding the statement that experiential education methods can improve learning effectiveness (Giac et al., 2017). The vast majority of respondents completely agree $(55 \%)$ with this statement, $25 \%$ agree while only 4/20 (20\%) students express a neutral opinion. Based on the survey results, students will mostly prefer to participate in experiential learning activities over traditional educational methods. The fact is that $50 \%$ of students completely agree, while only a small part (20\%) chose to be neutral or disagree. Besides, for the statement about whether experiential education helps to train students' soft skills, the majority of students completely agree $(60 \%)$, or agree $(30 \%)$ and only $2 / 17(10 \%)$ of which neither agree nor disagree (Table 2).

\begin{tabular}{|c|l|c|c|c|c|c|c|c|c|}
\hline No & \multicolumn{1}{|c|}{ Statement } & $\mathbf{1}$ & $\mathbf{2}$ & $\mathbf{3}$ & $\mathbf{4}$ & $\mathbf{5}$ & $\begin{array}{c}\text { Total } \\
\text { answers }\end{array}$ & $\begin{array}{c}\text { Total } \\
\text { score }\end{array}$ & $\begin{array}{c}\text { Average } \\
\text { frequency }\end{array}$ \\
\hline 1 & $\begin{array}{l}\text { EEM will help connect lecturers with } \\
\text { students more closely. }\end{array}$ & 0 & 1 & 6 & 8 & 5 & 20 & 77 & 0.25 \\
\hline 2 & $\begin{array}{l}\text { EEM will help improve students' } \\
\text { learning efficiency. }\end{array}$ & 0 & 0 & 4 & 5 & 11 & 20 & 87 & 0.28 \\
\hline 3 & $\begin{array}{l}\text { Students will enjoy being taught for } \\
\text { real-life situations through the EEM. }\end{array}$ & 0 & 1 & 3 & 6 & 10 & 20 & 85 & 0.28 \\
\hline 4 & $\begin{array}{l}\text { EEM will help practice soft skills for } \\
\text { students. }\end{array}$ & 0 & 0 & 2 & 6 & 12 & 20 & 90 & 0.29 \\
\hline & \multicolumn{7}{|l|}{} \\
\hline
\end{tabular}

Table 2: Degree of agreement with statements about Experiential Education Methods (EEM)

On the other hand, through a semi-structured form, a small interview conducted with 5 students on social networking sites showed different results than the survey (Weinberg et al., 2011). Most students when being asked if they have heard or learned about a teaching method called experiential education, answered that they have never heard of it $(60 \%)$ or heard but never learned (20\%). When being asked to comment on the necessity of this teaching method in the training program, the interviewees said that depending on the field of study, theoretical subjects are not necessary. Language learning, especially Japanese, is necessary, but others say that traditional education methods should be preferred instead of experiential learning.

For the next question: "In your opinion, what benefits will this method bring to students?", most of the interviewees' answers are confidence, initiative, and acumen (Weinberg and coworker, 2011). In addition, depending on the form of teaching, the corresponding ability will be developed, for example, with the form of debating, it will be skills of criticism, public speaking, etc. However, they also said that the method requires high speed so sometimes learners might take shortcuts without knowing why, and learn to cope more than to understand thoroughly.

With the most important pair of questions, related to the advantages and disadvantages of organizing experiential activities, many important factors have been mentioned. In terms of advantages, $40 \%$ of them said that a good promotion plan will attract more attention of learners, accompanied by an agreement between the parties such as with the institution, between lecturers and students, etc. On the other hand, there are also people who say that the pragmatic element is extremely necessary, that is, the idea of the organization must be feasible, and the knowledge should stick to reality. The common point of all the interviewees here, they do not think that the factor of funding, facilities will be important and should be considered because it depends on the scale of such an activity. which. This is in stark contrast to the results obtained from the survey, as the vast majority $(76.5 \%)$ chose the cost and facilities that will help the organization of the experience activities take place. more favorably (Figure 2).

Through surveys as well as interviews, some difficulties were reflected in the process of organizing experiential activities. While those surveyed from the questionnaire still chose funding and facilities as the most important determinants, the respondents did not (Figure 2). It is argued that this experiential method focuses on students, who are the beneficiary and the performer at the same time, so the most difficult part lies with this group. However, respondents found that this is not the case 


\section{GENERAL MANAGEMENT}

in Vietnam where students are still highly dependent on teachers (Giac et al., 2017). The next issue to be mentioned is the time, how to plan and arrange a suitable schedule for both students, lecturers, and institutions. Whether the difficulties are subjective or objective have a certain impact on the effectiveness of experiential education activities, thereby, finding a timely solution to overcome the problem is extremely necessary.

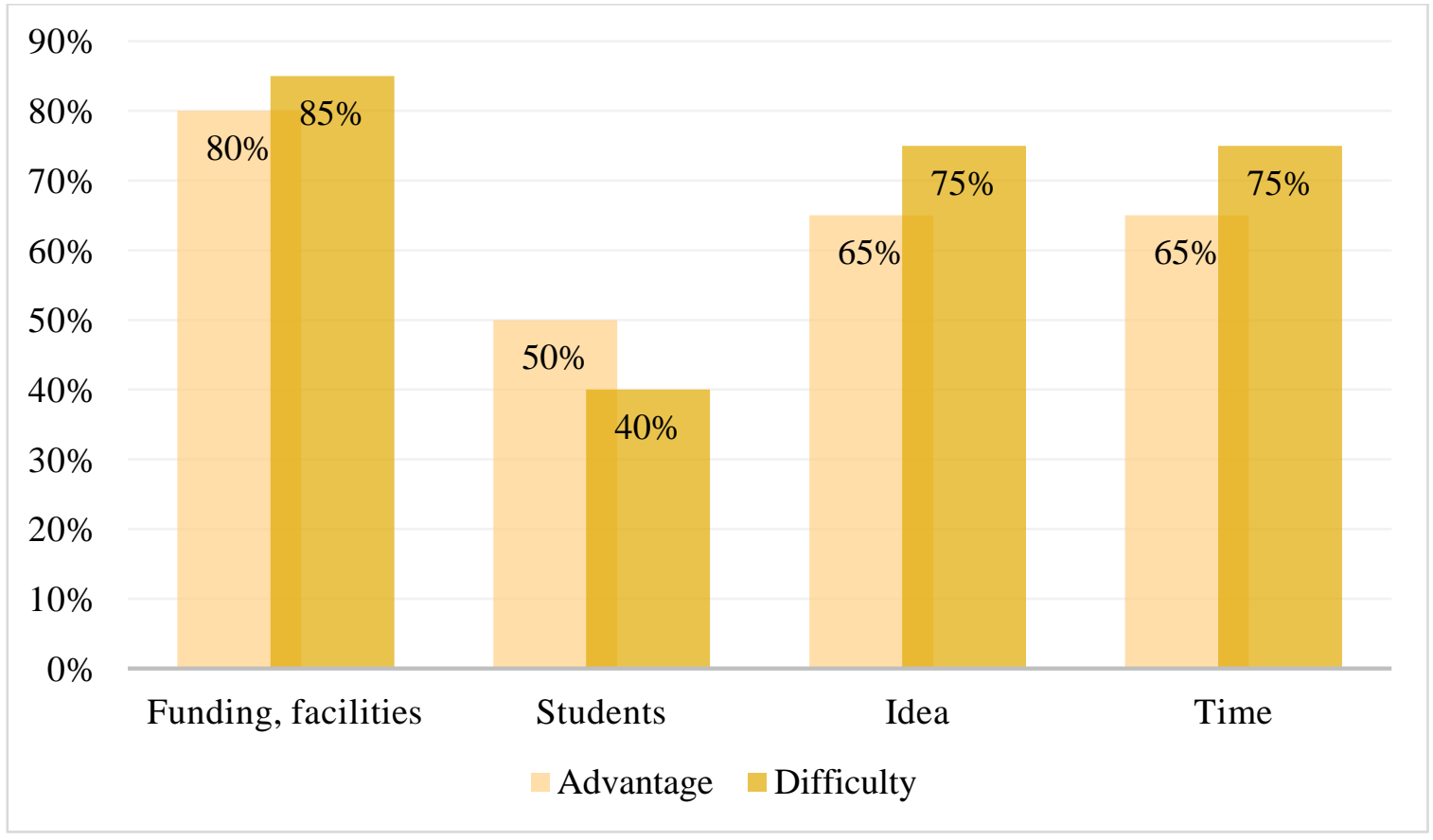

Figure 2: Advantages and disadvantages of organizing experiential education

\subsection{Some suggested solutions}

After analyzing the current situation and difficulties, combining survey opinions from students, a number of solutions have been proposed to solve problems affecting the effectiveness of organizing experience activities (Phuc, 2018).

Firstly, considering the human factor, this is always a difficult problem to solve because this is about how a community thinks about a certain thing. Many people believe that in the Vietnamese mind in general, teaching and learning activities often take place in the form of lecturers speaking and students listening, so this thinking needs to be changed, and the breakthrough is the best method. The best way to do that is by referring to experiential activities held at other universities, from which to learn and draw experience.

In addition, when participating in experiential activities, students must mobilize knowledge, skills, and general competencies to solve practical tasks. There are individual tasks, there are also tasks that require the cooperation of the whole team. Therefore, it is necessary to instruct students in skills such as teamwork, active listening, and feedback, notetaking skills, information gathering and processing, decisionmaking skills, etc. (Weinberg et al., 2011).

Secondly, make a complete and specific organizational plan, build a promotional campaign to attract the attention of students, comprehensively consider the factors of time, space, and estimate the majority of schools. In case of possible risks, always put the safety, experience, and interests of students first.

Third, the method of experiential education basically has the nature of collective activities in the spirit of self-control in order to develop the creative skills and individuality of each individual in the group. Thereby, forming students' ability to transform the learning process into the process of developing creative thinking (Giac et al., 2017). Therefore, in order to organize an experiential activity, the lecturer needs to create opportunities for all students to participate in the whole process of the event by performing all steps such as formulating ideas, building planning, preparation, organization, and performance evaluation (Boggs et al., 2007).

Fourth, the most suggested measure in the survey is calling for funding. However, this will be a bit difficult, moreover, the organizational funding will not be important for small and medium-sized activities, instead can take advantage of the resources available from friends, relationships around for the purpose of saving.

\section{Conclusion}

In summary, the research results have shown that most of the students of the Japanese Language major at FPT University in Ho Chi Minh City have had the right perception, expressed their desire to have the opportunity to organize and participate in the events and experience activities in different environments to help them be equipped with more useful knowledge, be active, discover, adjust themselves, promote and accumulate personal experiences through practical experience. At any given time, students are always at the center of the higher education process, all surrounding factors have their own role in organizing, supporting, and guiding the learning process to become effective and more developed. In general, the experiential education method is not only limited to a certain class scope but also a process that can connect traditional teaching methods with modern methods, make the teachinglearning relationship become more effective, and provide opportunities for students to develop more comprehensively. Although this study cannot generalize the entire educational environment when it only reaches a small number of students of the school, the results obtained can instead provide new and necessary data for future research along with practical proposed solutions to support the implementation of experiential activities. On the other hand, this teaching method should not be seen as a direct replacement for traditional teaching methods but as a complementary element to form a combination of tradition and modernity, between theory and 


\section{GENERAL MANAGEMENT}

practice.

\section{Limitations of the article}

The article still has certain limitations and hopefully, in the not too distant future, the article will be invested more carefully and properly.

\section{Acknowledgement}

Sincere thanks to the valuable contributions of lecturers and students who assisted in completing the survey as well as faceto-face interviews so that this article can be completed in the best way.

\section{References}

[1] Boumová, V. (2008). Traditional vs. modern teaching methods: Advantages and disadvantages of each. (Doctoral dissertation, Masarykova univerzita, Filozofická fakulta).

[2] Bradley, E. L. (2014). Choice theory and reality therapy: an overview. International Journal of Choice Theory and Reality Therapy, 5(1), 6-14.

[3] Giac, C. C., Gai, T. T., \& Hoi, P. T. T. (2017). Organizing the experiential learning activities in teaching science for general education in Vietnam. Journal of Chemical Education, 5(5), 180184.

[4] Phúc, N. T. N. (2018). Thực trạng tổ chức dạy học trải nghiệm của giảng viên Khoa Sư phạm, Trường Đại học Cần Thơ. Tạp chí Khoa học Trường Đại học Cần Thơ, 104-112.

[5] Piercy, N., Brandon-Jones, A., Brandon-Jones, E., \& Campbell, C. (2012). Examining the effectiveness of experiential teaching methods in small and large OM modules. International Journal of Operations \& Production Management, 32(12), 1473-1492. doi:10.1108/01443571211284205

[6] Boggs, J. G., Mickel, A. E., \& Holtom, B. C. (2007). Experiential Learning Through Interactive Drama: An Alternative To Student Role Plays. Journal of Management Education, 31(6), 832-858. doi:10.1177/1052562906294952

[7] Chiharu Hirata, Naoko Nakao, Kaori Shibata, Tomoko Yamamoto, Takashi Sawasaki, Yutaka Hasegawa, ... \& Yoshihiro Uchida. (2008). Questionnaire survey and analysis of students regarding early experiential learning of 6-year pharmacy education Medical Pharmacy, 34 (2), 204-213.Weinberg, A. E., Basile, C. G., \& Albright, L. (2011). The Effect of an Experiential Learning Program on Middle School Students' Motivation Toward Mathematics and Science. RMLE Online, 35(3), 1-12. doi:10.1080/19404476.2011.11462086

[8] Eyler, J. (2002). Reflection: Linking Service and Learning-Linking Students and Communities. Journal of Social Issues, 58(3), 517534. doi:10.1111/1540-4560.00274

[9] Rickinson, M. (2001). Learners and Learning in Environmental Education: A critical review of the evidence. Environmental Education Research, 7(3), 207-320. doi:10.1080/13504620120065230 